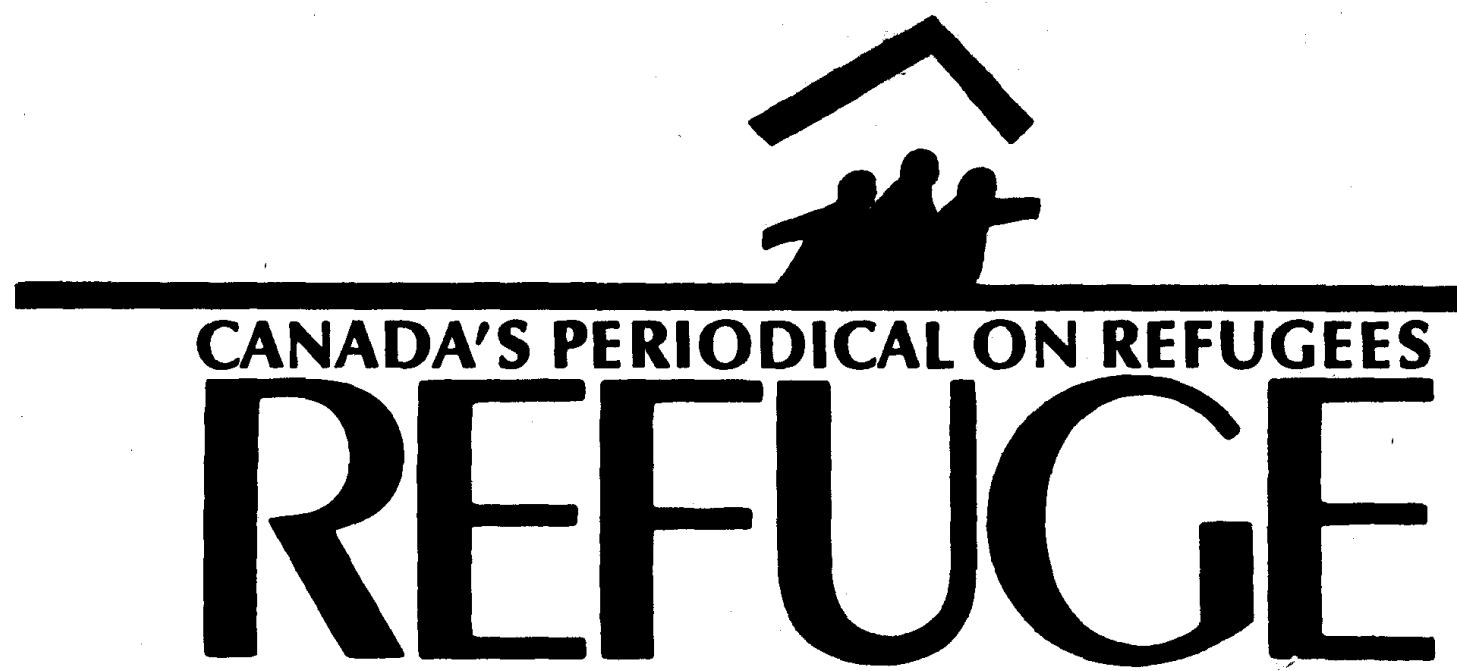

Vol. $14 \cdot$ No. 8

January 1995 Special Issue on Women Refugees-Part 2: Case Studies

\title{
Refugee Women and Repatriation: Perspectives from Southeast Asia
}

\section{Introduction}

Repatriation, which has become the main long-term solution of the United Nations High Commissioner for Refugees (UNHCR), is reflected in the refugee activities in Southeast Asia. However, as the High Commissioner remarked in 1993: "Relatively little has been documented on the specific issues facing women returning to their homes after years in exile" (ForbesMartin 1992, viii).

In this paper, I hope to contribute some scattered pieces of documentation in an effort to fill this knowledge gap. The paper is mainly empirical and draws on my eighteen months' work experience with UNHCR in Southeast Asia. It is based primarily on observations of and interviews with refugees, asylum seekers, returnees, and the staff of international agencies, governments, and the UNHCR. Knowledge has also been gained from genderawareness training seminars in the region and the available secondary literature. While the data have been gathered in the context of my profes-

\section{Kate Halvorsen}

sional activities for UNHCR, the views expressed in this article are entirely my own, and do not necessarily reflect the position of UNHCR.

Contrary to a broad range of evidence, it is still widely assumed in project planning and implementation that refugee assistance reaches everybody equally. Gender is one of the most significant differentiating and this paper will seek to identify and features in any society or community, analyze those aspects of the repatriation process which have or have not taken gender difference and gender relations sufficiently into consideration.

The following issues related to repatriation will be investigated: have demographic data about the refugee population been produced and used for repatriation planning purposes? Does counselling and information about voluntary repatriation reach

\section{Contents:}

Refugee Women and Repatriation:

Perspectives from Southeast Asia Kate Halvorsen

Elderly Mozambican Women Refugees in the Tongogara

Refugee Camp in Zimbabwe: A Case Study

Dodo Thandiwe Motsisi.

War, Ethnicity, and Violence Against Women Jadranka Cacic-Kumpes

Women's Groups in the Former Yugoslavia:

Working with Refugees Maja Korac

The Latin Ámerican Exile Experience from a Gender

Perspective: A Psychodynamic Assessment Marlinda Freire ... 20 


\section{REFUGE \\ YORK LANES PRESS Centre for Refugee Studies Suite 351, York Lanes York University 4700 Keele Street, North York Ontario, Canada M3J 1P3 Phone: (416) 736-5843 Fax: (416) 736-5837 Internet: refuge@vm1.yorku.ca Vol. 14 No.8 January 1995 \\ Editor C. MICHAEL LANPHIER Issue Guest Editors WENONA GILES ANDREA LOVE Assistant Editors VLADISLA V TUMIR MARK SWINDER Managing Editor ARUL S. ARULIAH Refuge is dedicated to the encourage- ment of assistance to refugees by providing a forum for sharing in- \\ formation and opinion on Canadian and international issues pertaining to refugees. Refuge was founded in 1981. \\ It is published ten times a year by York Lanes Press for the Centre for Refugee Studies, York University, Canada. Refuge is a nonprofit, inde- pendent periodical supported by private donations and by subscriptions. It is a forum for discussion, and the views expressed do not necessarily reflect those of its funders or staff. \\ All material in Refuge may be re- produced without permission unless copyrighted or otherwise indicated. Credit should be given to the author or source, if named, and Refuge. Sub- missions on rela ted issues are welcome for publication consideration. \\ Current subscription rates for one \\ year (ten issues) are: \\ Canada Can. $\$ 50$ \\ All other countries U.S. $\$ 60$. \\ (Cheques must be drawn on a Canadian or a U.S. bank.) Single issues are available at $\$ 6.50$ per copy. \\ Please enclose your purchase order or payment, made payable to York Lanes Press, with your order.}

ISSN 0229-5113 men and women equally, and who makes the actual decision to return? Are men or women systematically neglected in information dissemination in the refugee camps and in reintegration assistance during and after return? Is physical abuse by other refugees, government officials, pirates, or bandits during and upon return a gender-specific problem? Does monitoring include investigating the specific needs and concerns of special needs groups,such as female-headed households, elderly women, single minor mothers, and severely traumatized women? Are specific reintegration needs of women being addressed?

Historical and Political Context

Repatriation in the Southeast Asia region (also known as Indochina) is taking place to three countries of origin, Cambodia, Laos, and Vietnam. Gradually, as the political and economic situation has changed in all three coun tries of origin, the attitude of the international community with respect to the best durable solution for those remaining in the camps and detention centres in the region has also changed. It is now widely accepted by most players in the international arena, except for the asylum seekers and refugees themselves, that the best solution for the great majority is to return to their home country. The attitude towards going home varies among the three populations. The Cambodians wish to return to their country, provided there is peace. Some of the Laotians are willing to repatriate. The majority of the Vietnamese and the hill tribe Laotians oppose repatriation, although a growing number in both of these groups are signing up for voluntary repatriation as hopes of resettlement fade. The great majority of the Laotians and the Cambodians are in Thailand, while the Vietnamese are scattered in the region, with the majority in Hong Kong.

The Laotians

The number of Laotian refugees peaked in 1979 when 126,500 refugees and asylum seekers flooded into Thailand. As of May 1993, there were ap proximately 40,000 Laotian refugees in two camps along the Thai-Laotian border. A significant number of the households are female-headed. There is an important etlmic division between the so-called "lowlanders" and the "hill tribes." Ninety percent of the refugees belong to the hill tribes and the great majority of them to the Hmong tribe. Some of the Hmong groups fought with the Americans during the Vietnam war while others led the resistance force in Laos. The low-land Lao who are left in the camps today fled mainly for economic reasons and most of them have weak refugee claims. Since the great majority of the refugees are Hmong, the following issues mainly concern this group.

Social, economic, and political life in Hmong society is influenced by a very strong sense of cultural identity and is regulated by customary law. The Hmong are polygamous: most men have two or more wives. Women are responsible for domestic work and child care, and playa significant role in agricultural production and trade in Laos. In the camps, they are largely confined to their homes, and they seldom go to public meetings or gatherings. It is relatively difficult to get access to Hmong women, except through female Hmong-speakers who go on home visits. The women hold no positions in the camp leadership and the decision-making structures. There have been some attempts at establishing women's groups in the Laotian camps, but they have failed. It is uncertain whether this failure is due to the almost impossible task of mobilizing the "shy" women for such activities, or to a lack of awareness among staff. The literacy rate is low in general, but considerably lower for women than men.

Durable Solutions

The most important issue for the people remaining in the camps is to make a decision regarding repatriation to Laos or resettlement in the United States (for those who still have this

Kate Halvorsen works with UNHCR in Bangkok, Thailand.

Refuge, Vol. 14, No.8 Oanuary 1995) 
option). A common reason for the inability to make a decision is disagreement between husbands and wives. The male household head makes the official and public decisions for the household. Most often, he follows the decisions of his clan or other male leaders in the community. Customary law dictates that women must obey the husband and his clan. In cases where husbands have left the camp for indefinite periods of time, sometimes as long as several years, the wives still cannot make decisions about their future. Widows are in the same situationdecisions are made for them by the clan of the husband. Husbands leave the camps for various reasons: to be with another wife, to join the resistance in Laos, or to visit relatives or friends for indefinite periods of time. In such instances, some women request a divorce or separation in order to get their refugee status determination case split from their husband's. In split cases, where the wife refuses to follow the clan of the husband (including cases where the husband is dead or missing), the husband's clan retains custody of the children according to customary law.

A woman may wish to divorce for any number of reasons, as the following examples from my research indicate:

- A husband wants to go to the United States but his wife and four children want to return to Laos;

- An Hmong major's wife in one camp is determined to return to Laos while her husband in the other camp is living with another wife and will not let her repatriate;

- A widow with five children wishes to go to the United States, but her dead husband's family pressures her to return to Laos with them and marry her husband's brother;

- A husband returns after four years with the resistance movement in Laos, decides to resettle in the United States and wants his wife and two children to join him, while his wife has already signed up for voluntary repatriation with the two children;
- A husband left his wife and four children two years ago and she does not know what happened to him; she wants to repatriate but her husband's clan will not let her.

From the above examples, one can discern a tension between the voluntariness of repatriation on the one hand, and the principle of family unity on the other. The approaches of the UNHCR staff dealing with these problems vary, but in general they have adopted a non-interventionist, that is, a familyunity approach. Only when the husband has been absent for a substantial length of time does the staff regard the woman as the decision maker. Some have split cases upon request if the husband has been gone for more than one year. Others have been more restrictive and reluctant about splitting cases because it contradicts customary law and intervenes in the personal, and private sphere.

\section{Information and Counselling}

Information and counselling is associated with making decisions about repatriation. What kind of information is available and to whom? More specifically, does this information reach all categories of women?

Very few. women attend information meetings about the practical procedures of repatriation and the situation in Laos. Attempts have been made both to initiate meetings with women and to visit them in their homes. In general, the poorest and illiterate women are in great need of information about the issues involved. However, there has only been one Hmong woman among the camp staff and very few female Hmong speakers who could go on home visits or organize women into small discussion groups. As well, Hmong women lack time for consultation as their days are filled with household tasks and the production of handicrafts for income. Usually counselling is done with the head of household, with or without the rest of the family present. There have been a few attempts at targeting specific groups, such as widows and teenagers, as well as attempts to recruit more female Hmong-speaking staff to work with the women, but this has proven to be extremely difficult. A video has been planned for Hmong women, which should serve both to increase their level of information and to promote voluntary repatriation.

\section{Identification of Vulnerable Indi- viduals and Monitoring of Reinte- gration}

The Laotian repatriation is relatively small in comparison to the Cambodian operation, ranging between 100-150 and 350-400 individuals returning in groups about every two weeks. They go back either to existing villages or to group settlement sites. Three categories of vulnerability have been identified for special reintegration assistance purposes: those with severe or chronic illnesses, the physically and mentally disabled, and elderly or female heads of households in need of support. However, according to Hmong tradition, these vulnerable individuals are taken care of by the family and community. Little is known about the reintegration of the female heads of households, because few of those registered as especially vulnerable have returned.

The monitoring of returnees has continued, but there is no specific focus on the special concerns of women. At present, there are no female Hmong-speaking staff members in Laos. This should be a priority in the development of more gender-sensitive monitoring. In addition, nongovernmental organizations should be encouraged to report on and assist returnees in their areas of activity with specific focus on the reintegration of women, especially the most vulnerable among them.

\section{The Cambodian Repatriation}

The Cambodian repatriation, unique not only in the region but also by UNHCR standards, was one of the most organized and structured largescale repatriation operations ever undertaken. It began on March 30, 1992 and was completed just over a year later, by which time approximately 
380,000 refugees had been repatriated. Fifty percent of the camp population was under the age of fifteen. The gender distribution was relatively even with a slight majority of men. Data from 1990 show that 21 percent of the households were female-headed (Thorn 1991). The majority of women were illiterate, and virtually all the poorest women and most of the female heads of households were illiterate. Little training or education were offered to these women while they were living in the camps.

In the camps, women were responsible for domestic work and child care while men held formal decision-making positions. A much greater percentage of men than women had jobs with the non-governmental organizations (NGOs) in the camps and participated in training and education. A women's organization, the Khmer Women's Association (KWA), existed in each of the camps and was involved in social work and training related to household and childrearing activities, such as knitting, sewing, crocheting, and child health. Most of these training activities, however, were not useful for income generation upon return.

\section{Planning for the Repatriation of Vulnerable Individuals}

A study was commissioned by UNHCR on "the repatriation and reintegration needs of vulnerable female heads of household and other vulnerable individuals living in the Cambodian refugee and displaced persons camps along the Thai-Cambodian border" (Thorn 1991). This study was carried out at the end of 1990.

From those identified in the UNHCR study, a decision was made to focus on the most vulnerable, i.e. those who would not survive during movement and reintegration without special assistance. Thus the category of "Extremely/Especially Vulnerable Individuals" (EVIs) was created. The criteria for selection were consequently very restrictive. All female heads of household in the border camps were interviewed. Those without relatives, family, or friends in the camp with whom they could return or be reunited inside Cambodia, with children under ten years of age, and who were unable to cope with the everyday household chores (feeding dependents, cleaning, washing, carrying heavy loads), were registered.

Less than five percent of the total number of female heads of households were registered as EVIs, thus excluding the large majority who were still potentially vulnerable upon return, such as those who might be abandoned by their support group; those who might not find their family or relatives upon return; and older children who might not help as expected in the household. In other words, of the total number of female heads of household in the border camps, a number of those not identified as EVIs became EVIs upon returning to their country of origin. In addition, some women who cash. Videos were shown, information meetings were held, and cross-border visits of international and local staff took place in order to create links between organizations on both sides of the border.

In preparation for return, the KWA went to Cambodia on a ten-day visit to meet with the Women's Association of Cambodia (WAC). They held formal meetings and went on field trips to visit WAC projects scattered throughout the country; these contacts resulted in a joint political declaration about their common goals and interests as economic and political actors in the future of Cambodia. This declaration was formally submitted to the Supreme National Council (SNC). As a result of a small informal survey among poor female heads of households in the border camps, to investigate the level of information about

\section{Less than five percent of the total number of female heads of households were registered as EVIs, thus excluding the large majority who were still potentially vulnerable upon return, such as those who might be abandoned by their support group; ...}

were not heads of households in the camps were abandoned by their husbands or lost their husbands during the first year in Cambodia.

A rough estimate, based on my own interviews with more than two hundred returnees and visits to most of the major settlement sites, indicates that 30 to 40 percent of the households were female-headed. This is the same percentage estimated for the general population in Cambodia (Ledgerwood 1992).

\section{The Information Campaign}

An information campaign was launched in the border camps in order to better prepare the returnees for the realities of life in Cambodia, and to provide information about the type and duration of the assistance they would receive. The assistance consisted a year of food supplies (rice, oil, salt, and canned fish), household utensils, and either land for cultivation, a house plot with house materials, or repatriation and conditions in Cambodia, an educational video about returnee women was made called "Cambodia-Portrait of Returnee Women." The video was meant to provide the necessary information to prepare for a return, and was shown on a mobile unit in the camps so that widows and poor women did not have to move far from their homes in order to see it.

\section{Assessment}

As the end of the repatriation phase approached, the reintegration situation of vulnerable returnees was assessed in order to procure additional long-term assistance. Food assistance was provided for four hundred days, meaning that from April 1993 onwards food provisions would end for an increasing number of returnees. Their survival would depend on the degree of self-sufficiency acquired during the first year back in Cambodia. 
The majority of the female heads of households were found to be coping adequately. Many joined families and relatives who were earning a living; some had been able to start an incomegenerating activity; those few who received land engaged in agricultural activity; some had managed to save money or stock up on extra rice; others did small animal husbandry. There were no reports of persecution, but those who had gone to so-called "nogo" areas (defined by UNHCR as unsafe and unsuitable for return) were worried about mines and fighting.

However, a significant number of female heads of households were facing problems that may become serious when their food assistance expires. These included: no jobs; no land for cultivation or for house plots; no cash to invest in income generation; desertion by spouse upon return (who frequently took the remaining food coupons and cash); inability to complete the building of houses because of insufficient materials; the need to borrow money to transport building materials and rice; family problems living in a house shared with siblings, parents, and relatives with many children and mouths to feed; caring responsibilities for the handicapped and elderly; a few severe traffic and land-mine injuries resulting in disability and high medical costs; high funeral costs for deceased husband; a few cases of severe mental illness.

The main problem, however, for many returnees, but most seriously affecting the female heads of households, is lack of income. Most widows who were in need of assistance for income-generating activities had ideas about what to do for a living. Virtually all of them had realistic schemes for starting micro-businesses, such as cake making, grocery stalls, sewing, weaving, small animal husbandry, vegetable farming, or selling flowers. These activities all require capital, and most returnees were given cash (as opposed to those who chose a house plot or land for cultivation), which was meant, among other things, to start an incomegenerating activity. However, the al- lotment of cash was often spent on other necessities, such as transporting belongings and rice rations, paying school fees, and buying additional food and clothes.

Monitoring of the vulnerable and EVIs by female Khmer-speaking staff is essential. In addition to the general information gathered about everyone, staff should make inquiries related to the specific situation of female heads of households including when, why, and how their husbands left or died, which belongings and resources they left behind, how women are coping in their absence, how many family members they feed and care for, and any special handicaps or illnesses of family members. Other international agencies should also take responsibility for following up on the vulnerable adults. There are few income-generating projects that focus on the poorest and most needy female heads of households. NGOs and other UN agencies should be encouraged to address the needs of this group of returnees and to locate projects in areas of high returnee concentrations. In some places, small credit or loan schemes are sufficient, while in other places income generation should be included in a broader community development project.

\section{The Vietnamese}

The Vietnamese refugees and asylum seekers have undoubtedly received the most publicity and attention in the region from the international community. A total of 87,800 refugees and asylum seekers still remain in camps or detention centres in Indonesia, Malaysia, Hong Kong, the Philippines, and Thailand, with the majority $(44,300)$ in Hong Kong. The demographic profile is much the same throughout the region; around two-thirds of the population is male and one-third is female, most of them between fifteen and forty years of age.

Those now living in refugee camps or detention centres arrived after the deadline for automatic refugee status in 1989, and the majority will not receive refugee status. An increasing number of asylum seekers are conse- quently facing the decision to return to their country of origin. As in the case of the Laotians, the major issue determining their situation is voluntary repatriation.

The gendered division of labor among the Vietnamese is also characterized by women taking responsibility for domestic work, certain aspects of agricultural production, and trade. Society is centred around the family and men enjoy higher status than women.

Traditionally, women did not take part in formal decision making, although significant changes have occurred in Vietnam following the change of regime in 1971, and economic and political reforms have been implemented in the last twenty years. In the camps, fewer women than men have been involved in skills training and education. Most of the paid jobs available in the camps and detention centres have likewise been occupied by men.

Women's groups have been established in most of the Vietnamese camps and detention centres, with varying success. Community leadership structures differ from camp to camp, but generally women's participation in decision making is very limited throughout the region. Women's groups are involved in social activities, but the little training they do get very seldom involves learning an incomegenerating skill that they could use upon return. The training has been in such areas as hygiene, cooking, child care, and psychosocial activities. Lately, two needs assessments of women have been undertaken, one in the Philippines and one in Hong Kong, which highlighted their need for job opportunities and income-generating skills.

\section{Voluntary Repatriation Counselling}

Information dissemination and counselling for voluntary repatriation varies from country to country and camp to camp, but one common feature is that women participate to a very limited degree in information meetings, video showings, or discussions. Indi- 
vidual women and women's groups have expressed the need for more specific information about the situation for women regarding jobs, training, education, child care, education of children, daily life, cultural, political, and economic conditions in Vietnam affecting women, and about projects for women returnees. However, little of this information has been available, and what exists is difficult to access. The use of discussion groups for women, single mothers, non-refugees, and youths has been attempted in a few places, but is not a common practice.

It has also been reported from many places in the region that the proportion of voluntary repatriation candidates is higher for men than for women. When a couple disagrees about voluntary repatriation it is more often the woman who resists return rather than the man. There are several reasons for this: women are often convinced that they will have a better and easier life in a resettlement country, and that they will be freer and more independent. As well, they do not have enough information about recent changes in daily life in Vietnam and the extent to which development assistance will be available to them upon return.

The major social problem in all camps and detention centres is domestic conflict, and this is sometimes the consequence of disagreement about repatriation. Non-intervention and family-unity approaches dominate in the attempts by international staff to solve the problems.

\section{Identifying Vulnerable Groups}

The identification of vulnerable adults preparing for return to Vietnam has proceeded on a case-by-case basis except for two categories: unaccompanied minors, and survivors of violence.

The great majority of female survivors of violence have been subjected to severely traumatizing acts of violence (most often including rape or multiple rapes) as a result of one or more piracy attacks during the flight from Vietnam. The victims may feel paralyzed by terror, suffer both physical and emotional pain, feel intense self-disgust, powerlessness, apathy, or denial. The trauma may not be temporary and could be aggravated by insensitive medical and legal procedures or inappropriate follow-up. Most of the survivors have been diagnosed with Post-Traumatic Stress Disorder (PTSD); others suffer from depression, grief, anxiety, and some from psychosis. In addition, there are a number of women who have suffered severe sexual or other physical abuse while in camp. Physical protection of women in the Hong Kong detention centres and camps has been a serious and widespread problem.

Monitoring and follow-up are difficult given the extremely sensitive nature of the victims' situation. Sexual assault most often leads to stigmatization because in Vietnamese society, as in many others, blame is placed on the victim, not the offender. The victims are also discouraged by their culture and religion from revealing the assault or openly discussing the experience, and thus are also often unwilling to identify and prosecute the offender. Victims often develop feelings of guilt and self-blame, and prefer to keep the incident a secret, especially when returning to Vietnam. The type of followup these women require must be very discreet to avoid mistreatment and stigmatization by their families and communities.

There are two other areas of concern. Many young girls and women who had pregnancies "of convenience" in order to increase their chances of being resettled, and were subsequently denied refugee status, will return to Vietnam single, with one or more children. As well, a significant number of prostitutes from all camps and detention centres, the largest concentration being in Hong Kong, will also be returning. These two groups of women are stigmatized in much the same way as the survivors of violence and may therefore wish to be anonymous upon return. Most do not want to go back to families or places of origin and will need special reintegration assistance to obtain employment, a place to live, and child care.

\section{Conclusion}

Two issues emerge as barriers to successfully repatriating and reintegrating women or specific groups of women: information production and dissemination, and the insufficiency and inadequacy of reintegration projects, especially vis-à-vis income generation in the country of return.

Insufficient information dissemination leads to the question of whether it is possible for women refugees to make informed decisions with respect to repatriation. Related to this problem is the fact that these women participate minimally in decision-making structures. One consequence of this is the dependency syndrome, which may be further perpetuated in development projects in the country of return. A related issue is the prevalence of gender relations in the camps that may be more conservative and traditional than in the countries of return. The camps are socially artificial and static, whereas ongoing rapid social change in the home country is significantly affecting gender roles. Both camp staff and population may perpetuate the norms and traditions of the past.

"It is generally assumed that refugee women will be a force for voluntary return if given the opportunity" (Forbes-Martin 1992, 65). I would conclude that in Southeast Asia they are still not given this opportunity, although attempts are being made. Cultural traditions, the rule of customary law, camp administration and organizational structures, illiteracy, inadequate information, inadequate reintegration projects, lack of skills training, and non-participation, are all barriers. Changing the role female refugees and asylum seekers play in the repatriation process is difficult, but some things can be done.

The focus for changing the situation should be on the country of return and the establishment of reintegration programs there. These programs should concentrate on income-generation combined with literacy training. In designing reintegration projects, one must bear in mind that the majority of 